\title{
Rooftop and Indoor reception with transmit diversity applied to DVB-T Networks: a long term measurement campaign
}

\author{
R. Di Bari, M. Bard, A. Arrinda, P. Ditto, J. Cosmas, K.K. Loo, and R. Nilavalan
}

\begin{abstract}
Although transmit Delay Diversity (DD) can provide a gain in indoor and other Non Line of Sight situations (NLOS), it can introduce degradation in rooftop reception. In fact, when the Ricean $K$ factor of the channel is significantly high (e.g. Line of Sight reception), the channel performs similar to an AWGN channel where the performance degrades due to $\mathrm{DD}$ that artificially increase the fading. This paper investigates through practical evaluation the impacts of Transmit DD on LOS and NLOS stationary reception. Then, it studies 2 techniques to reduce the degradation performance in LOS while aiming to keep the same diversity gain in NLOS reception.
\end{abstract}

Index Terms - Performance evaluation, Field trials and test results, Set-top box

\section{INTRODUCTION}

C urrent broadcast TV networks have been designed to enable reception by rooftop antennas, while next generation digital TV service providers that target mobile and fixed reception are finding that coverage indoors and in areas of Non Line Of Sight (NLOS) is a fundamental requirement. It is essential that such networks are designed cost-effectively and with minimized environmental impact. Multipath can result in severe fading in NLOS reception situations. The use of transmit diversity techniques with multiple antennas (MISO) have long been proposed to improve the performance and capacity of wireless systems. In Transmit Delay Diversity (DD), the same information is transmitted from both antennas simultaneously but with a delay of several OFDM symbol intervals $\mathrm{T}$, to overcome the effects of flat fading by reducing the probability of observing deep fades at the receiver [1]. Although DD can provide up to $7.5 \mathrm{~dB}$ gain in NLOS situations [2], it can introduce degradation in LOS situation. When the Ricean K-factor component of the channel is significantly high, the channel performs similar to an AWGN channel where the performance degrades due to DD that artificially increases the fading. This phenomena degrades the rooftop reception and it can make unattractive the adoption of DD techniques for broadcasting where both NLOS and LOS scenarios needs to be considered. To overcome this problem, [3] suggests several techniques based on a spectrum shaping of transmit diversity signal to mitigate the negative impact of transmit DD in LOS while aiming to maintain the same performances in NLOS. The main contributions of this paper are the analysis of the effectiveness of these new techniques through field measurements.

\section{THEORETICAL GUIDELINES}

In [4] it is showed that to achieve transmit diversity gain, the signals from different antenna elements should be sufficiently uncorrelated, e.g. at least with a correlation smaller than 0.7. A sub-optimal gain is obtained with a cross correlation of 0.25 . The decorrelation of the channels can be achieved by deploying the two transmit antennas with a spatial separation higher $20 \lambda$ as shown in [5]. Thus, a diversity gain is expected to be observed in NLOS situations assuming that the observed signals have uncorrelated or quasi-uncorrelated fading. In LOS or near LOS conditions, the respective signal paths between spatially separated antennas and the mobile receiver are likely to be correlated to a certain degree because of insufficient multipath in the channel. The transmit diversity techniques are effective in the NLOS situations where the Kfactor is small valued. Moreover, if the K-factor is significantly high (and the channel is subsequently highly correlated) the performance gets worse than SISO. This is because the correlated signal replica creates deconstructive fades at the receiver, resulting in a diversity loss. Figure 1 shows the average power profile at the receiver side for SISO and MISO transmission on a reference AWGN channel. In the MISO case, it is possible to see the deconstructive interference fades.
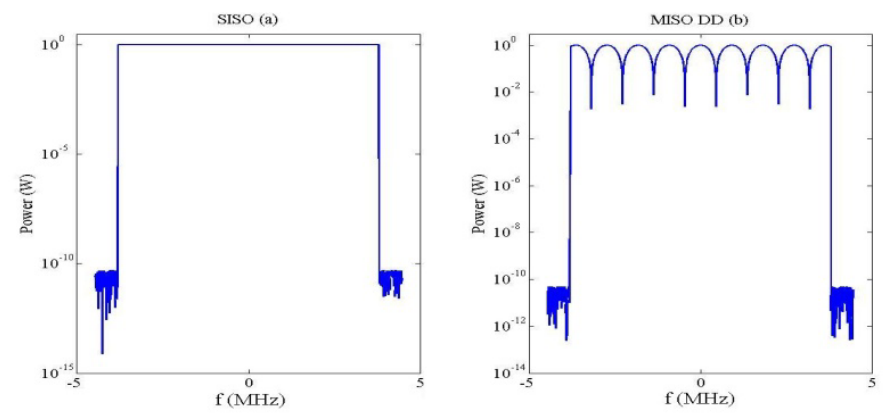

Figure 1: Average power profile for the SISO (a) and MISO DD (b) on AWGN channel case for $2 \mathrm{k}$ mode 

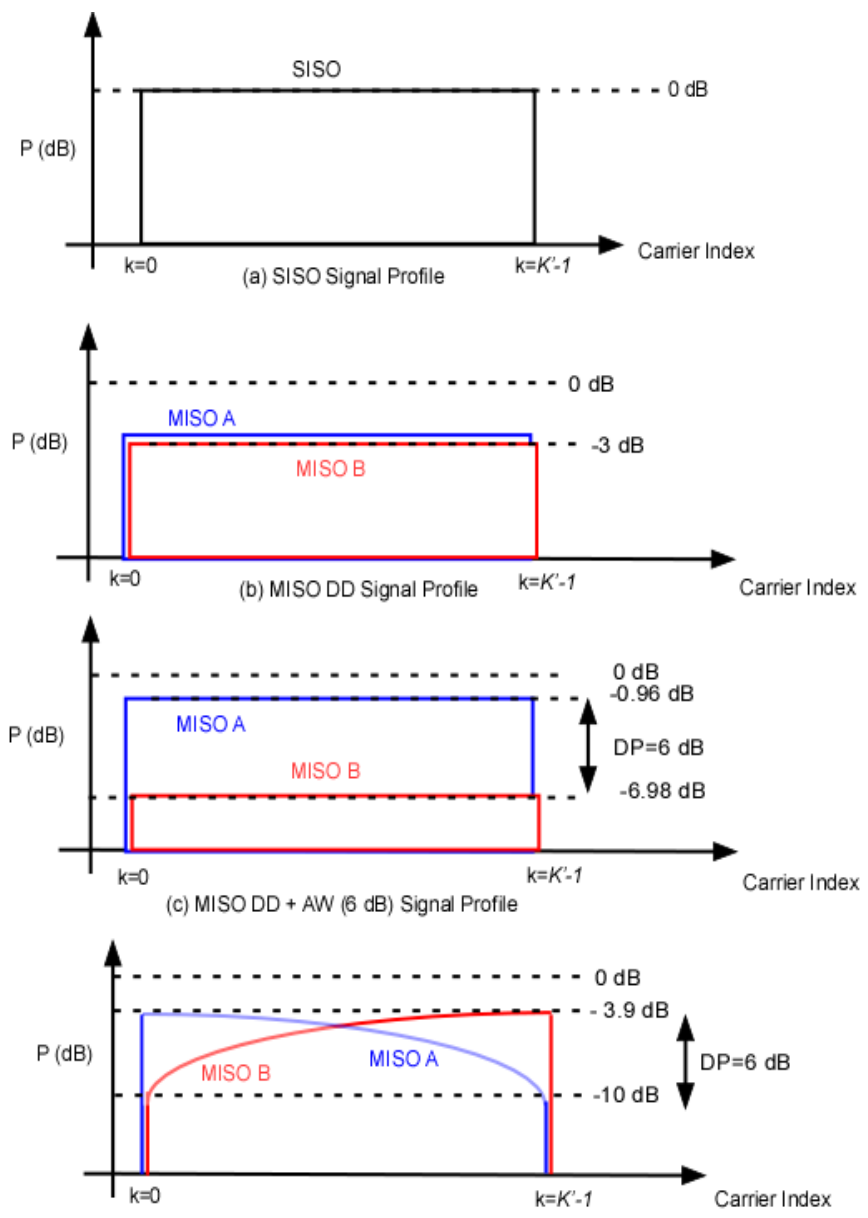

(d) MISO DD + SS Signal Profile

Figure 2: Signal Spectrum Profile comparison

To mitigate the diversity loss, some techniques have been developed in previous research work. For instance, [6] observes that the NLOS gain for a two branch system is the highest in the case of both branches having equal power. Even for the case with power differences of $6 \mathrm{~dB}$ between both branches, the NLOS gain was still appreciable versus the single Rayleigh scenario. Starting from this principle, it is envisaged that unbalancing the two diversity signal powers will mitigate the degradation in LOS reception while keeping a significant gain in NLOS. Reference [3] proposes two signal profiling techniques namely, Amplitude Weighting (AW) and Spectrum Shaping (SS) profiling.

- In AW profiling, the power transmitted from each transmit antenna is deliberately unbalanced. (see Figure 2(c)). [3] shows that a $\Delta P=6 \mathrm{~dB}$ weighting factor between the two transmitted signals is expected to provide the best trade-off among LOS degradation reduction and NLOS gain. A $6 \mathrm{~dB}$ weighting reduces the LOS degradation (compared to SISO) at high Kfactor from $5.5 \mathrm{~dB}$ to $1.8 \mathrm{~dB}$ while reducing the NLOS gain from $4 \mathrm{~dB}$ to $3.5 \mathrm{~dB}$.

- A modification to the AW profiling is the SS profiling, an amplitude profile that varies across the signal spectrum is applied. The intention is to achieve a power profile with $6 \mathrm{~dB}$ difference among subcarriers transmitted from each antenna. This technique produces characteristic "hills" and "valley" profiles along the signal spectrums. In this way, the interference can be minimized in high K-factor situations but the same average power can be maintained in each channel for optimal low K-factor performance.

In these field trials, the two signal profiling will be performed by the Diversity Unit described at later in this paper with a 16 tap filter. Figure 2 shows a schematic of the transmitted signal. Figure 2(a) shows the SISO profile, assuming a $0 \mathrm{~dB}$ power. Figure 2(b) shows the two MISO DD signal, flat and with a power of $-3 \mathrm{~dB}$ to maintain the same total transmitted power of SISO (e.g. 0 dB). In Figure 2(c) the two diversity signals are $6 \mathrm{~dB}$ unbalanced, having the $80 \%$ and the $20 \%$ of SISO EIRP. In Figure 2(d) the two diversity signal have a maximum of $6 \mathrm{~dB}$ difference in power level among carriers transmitted from each antenna.

The results presented in [3] will be used as general reference guidelines along this paper. They are estimated by comparing the Bit Error Rate at QEF condition for a particular indoor channel model with relatively small Doppler shift although the results presented in this chapter are estimated by using the $E S R_{5 \%}$ as defined in [7].

\section{EXPERIMENTAL NETWORK SET-UP AND METHODOLOGY}

This section describes the operator based and the remote controlled set-up. The transmitter was located at Brunel University in Uxbridge, in the west outskirts of London, 1.2 $\mathrm{km}$ south of Uxbridge. The field trial used two power amplifiers, rated at $100 \mathrm{~W}$, feeding a linear array of directive antennas. In the tests we compared quality of reception in the measurement area when either all power was transmitted from a single antenna (Single Input Single Output) or half power from each of 2 separate antennas (Multiple Input Multiple Output). The EIRP was $20 \mathrm{dBW}$ for both the single transmitter and dual transmitter (MISO) configurations on channel 53 which has a central frequency of $730 \mathrm{MHz}$ and bandwidth of 8 $\mathrm{MHz}$. A linear array of directive antennas were installed on top of one of the University buildings (named Tower D) pointing toward the east. The antennas are horizontally polarized panels with a gain of $12 \mathrm{~dB}$, a half-power beamwidth of $53^{\circ}$ degrees in the $\mathrm{H}$ plane and $24^{\circ}$ degree in the $\mathrm{V}$ plane. The antennas radiation pattern is presented in [8]. A maximum number of two antennas (out of five) were active at any time. The horizontal spatial separations between active antennas could be selected from 7 to 20 wavelengths.

The DD coding and the spectrum shaping were introduced by the custom designed Broadreach Diversity Unit. The receiver is composed of a receiver antenna and a Monitor Station (MS) connected to a laptop. For rooftop type experiments, the Omni-directional antenna was replaced with an $11 \mathrm{dBi}$ directional antenna [9]. The receiver can also be connected through an IP network to conduct automatic tests over a long period of time. A set of receivers were deployed within the Brunel University Network, e.g. within the range of radio 
coverage in the sites characterized previously in [5] by the short-term trials. Each MS embedded two DVB receivers and two receiving antennas can be connected per each MS. Each Monitor Station had a serial number and MAC address and was located in a specific environment which is identified with Ethernet Port number and is assigned a fixed IP address. The receivers are connected to the IP network to send the measurement reports periodically to the Control, Monitor and Process Applications (CMPA), which is a set of Matlab based routines, designed to manage one or more Monitor Station(s).

The main idea is to estimate the $E S R_{\%}$ criterion for SISO and MISO received signals and to compare the $E S R_{5 \%}$ thresholds. Generally an integration time of 2 minutes per each $E S R_{\%}$ estimation was found to be adequate for most scenarios and rendered a stable and accurate measure. The MS was incorporated with a programmable step attenuator. To determine the $E S R_{\%}$, the signal power was gradually reduced by increasing the attenuation of the receiver input attenuator value until the $E S R_{5 \%}$ threshold was exceeded. The step attenuator range is from $0 \mathrm{~dB}$ to $30 \mathrm{~dB}$. The receiver was located in a fixed position (e.g. stationary reception condition). Although a stationary channel is obviously typical for the rooftop reception, it is also believed that a stationary channel is a likely scenario for indoor digital TV. The channel can be time variant since the scatters around the receiver are nonstationary. The time variability of the channel can depend on people, cars moving and foliage moved by the wind in the case of areas with trees in between the transmitter and the receiver. The vegetation impact is more effective during summer, when trees have full foliage [10].

\section{Test Site Description}

This section describes the four sites where measurements were performed. Two sites were chosen within the Brunel's University Campus to be connected to the remote controlled network (see details in Table 2) while the Horseden Hill site is $10.2 \mathrm{~km}$ distance from the transmitter (see details in Table 2).

\begin{tabular}{|c|c|c|c|c|c|c|c|}
\hline & 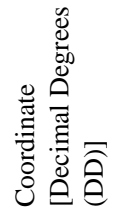 & 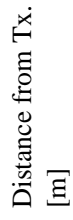 & 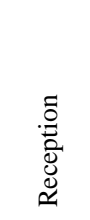 & 莺 & 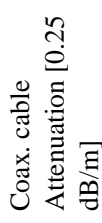 & 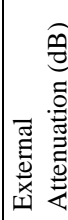 & 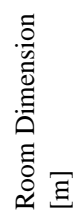 \\
\hline $\begin{array}{l}\text { Pro- } \\
\text { Active } \\
\text { office } \\
\text { in } \\
\text { Sports } \\
\text { Centre }\end{array}$ & $\begin{array}{l}51^{\circ} 31^{\prime \prime 5} \\
6.41^{\prime \prime} \mathrm{N} \\
0^{\circ} 28 ’ 12 . \\
69 \text { '’ } \mathrm{W}\end{array}$ & 298 & $\begin{array}{l}\text { Office } \\
\text { Indoor } \\
\text { NLOS }\end{array}$ & $\begin{array}{l}\text { Omni } \\
\mathrm{H} \\
\text { plane }\end{array}$ & $\begin{array}{l}0.125 \\
\text { [for } 0.5 \\
\mathrm{~m}]\end{array}$ & 0 & $\begin{array}{l}10 x \\
10\end{array}$ \\
\hline $\begin{array}{l}\text { Sports } \\
\text { Pavilio } \\
\text { n } \\
\text { Office }\end{array}$ & $\begin{array}{l}51^{\circ} 31^{\prime} 4 \\
4.66^{\prime \prime} \mathrm{N} \\
0^{\circ} 28^{\prime} 48 . \\
61^{\prime \prime} \mathrm{W}\end{array}$ & 698 & $\begin{array}{l}\text { Office } \\
\text { Indoor } \\
\text { NLOS }\end{array}$ & $\begin{array}{l}\text { Omni } \\
\mathrm{H} \\
\text { plane }\end{array}$ & $\begin{array}{l}0.125 \\
\text { [for } 0.5 \\
\mathrm{~m}]\end{array}$ & 0 & $\begin{array}{l}1.8 \mathrm{x} \\
3.5\end{array}$ \\
\hline
\end{tabular}

\section{A. Test sites within Brunel's Campus}

The measurement area is representative of a typical suburban area. All the receivers on the Brunel campus are within a range of $1 \mathrm{Km}$. The test sites are briefly detailed below.

Pro-Active Office in Sports Centre: The room is approximately $10 \times 10 \mathrm{~m}$. The antenna was placed on a cabinet at 1.90 meters from the ground, beside the wall. There are large windows on the south side.

Sport Pavilion Office: The room is approximately $1.80 \times 3.5 \mathrm{~m}$. The antenna was placed on a cabinet at 1.50 centimeters from the ground, beside the wall. There is a small window on the west side.

In Figure 3, the circle indicates the position of the receiving antenna in the reception sites, namely (a) in the Sport Centre Office and (c) in the Sport pavilion indoor office.

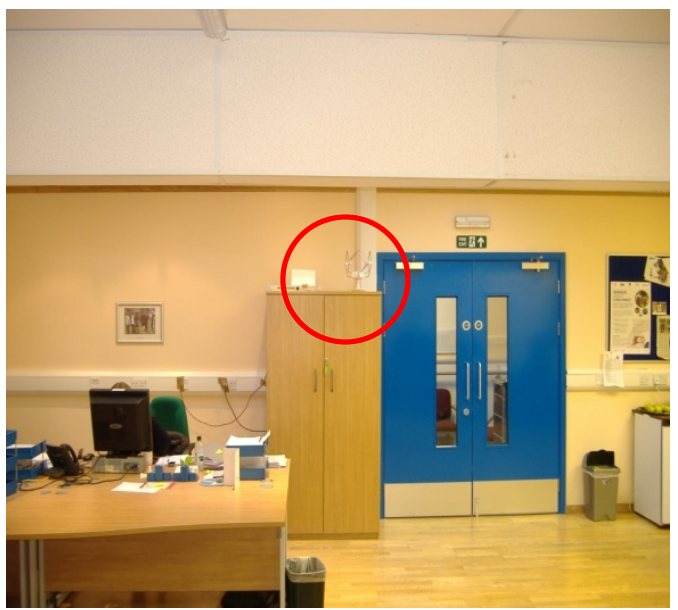

(a)

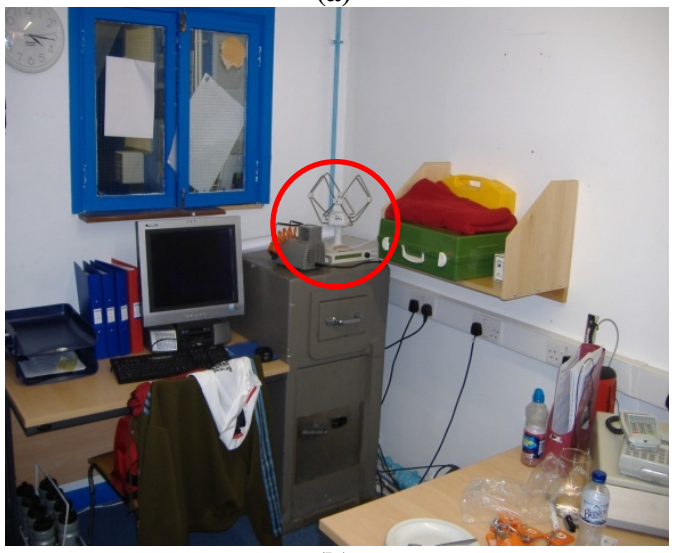

(b)

Figure 3: Sport Centre office indoor reception (a), Sport pavilion Rooftop antenna (b) and Sport pavilion indoor office reception (c)

\section{B. Horseden Hill site (long range)}

A test site for these measurements was selected on a hill some distance away from the transmitter. The hill was at a height that would provide similar performance to a rooftop mounted antenna. The distance was over $10 \mathrm{~km}$ from the transmitter, compared to the maximum range for driving measurements of between 1 and $2 \mathrm{~km}$ presented in [5]. The reception equipment also included a Global Position System (GPS) receiver. The antenna is connected to the receiver with 
a 2 meter long coaxial cable, adding an attenuation of $0.5 \mathrm{~dB}$. The receiver includes a programmable step attenuator. As detailed earlier, the attenuator is needed to gradually increase the number of errored seconds without reducing the EIRP at the transmitter. The main characteristics of the reception site are summarized in Table 2.

TABLE 2: Details OF HoRSEDEN RECEPTION

\begin{tabular}{|c|c|c|c|c|c|c|c|}
\hline & 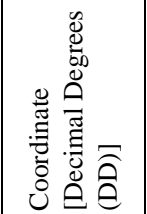 & 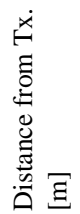 & 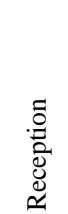 & 莬总 & 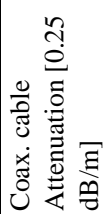 & 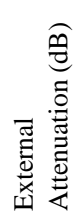 & 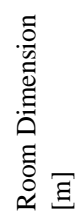 \\
\hline 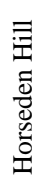 & 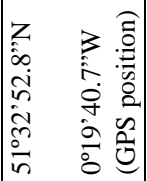 & 10.2 & LOS & 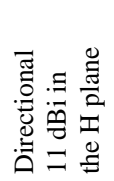 & 0 & 0 & N/A \\
\hline
\end{tabular}

The terrain elevation variation is $33.4 \mathrm{~m}$ (e.g. the variation in height between transmitter and receiver). The altitude geomap data are taken from internet [11]. The propagation mode is LOS, with minimum clearance of 0.1 of the First Fresnel Zone at $1.9 \mathrm{Km}$. This value is estimated by using a free radio planning tool available at [12]. Figure 4 shows the receiver antenna and the test site at the top of hill.

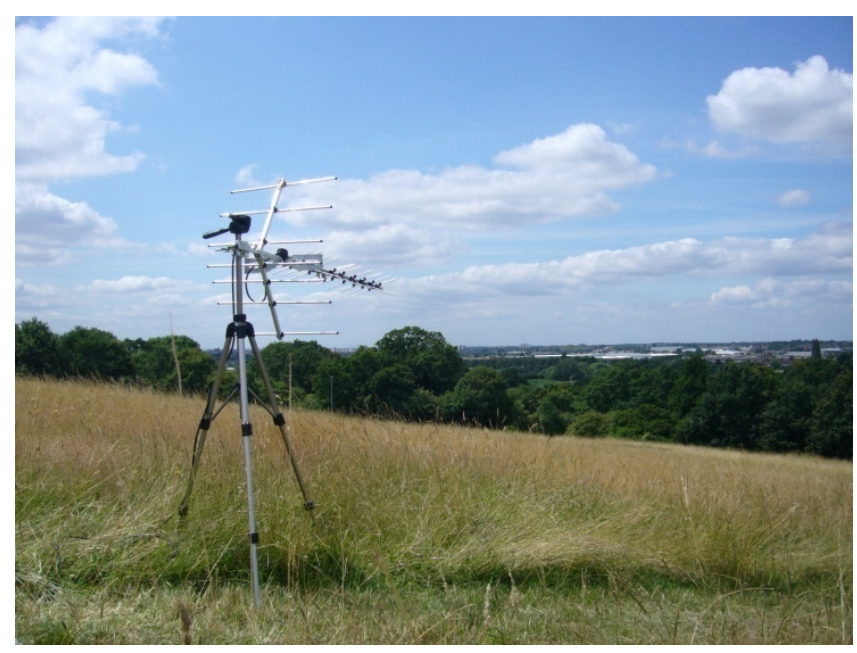

Figure 4: Horseden LOS antenna Reception

\section{Measurement Results}

This section details data analysis of the measurement results. The $E S R_{5 \%}$ estimation of the Horseden Hill, Rooftop and Office reception sites are presented and the diversity gain was calculated by comparing the fade.

\section{A. Rooftop LOS Horseden Hill Measurements}

The median measured receiver power with $0 \mathrm{~dB}$ attenuation among all the tests was about $-75.1 \mathrm{dBm}$, The estimated receiver fade margin $\tilde{M}_{F}$ corresponds to the excess attenuation needed to degraded the SISO performances up to the $E S R_{5 \%}$ visibility threshold, namely $A t t_{5 \%}$. Figure 5 shows the Errored Second Ratio (ESR\%) scan vs. input attenuation for LOS reception for SISO and different MISO spectrum profiles for 16 QAM constellation. To exceed the visibility threshold, it was required an excess attenuation of about 12.5 $\mathrm{dB}$ for $16 \mathrm{QAM}$ and $20.5 \mathrm{~dB}$ for QPSK. These results are compared with the $12.6 \mathrm{~dB}$ and $17.6 \mathrm{~dB}$ provided by the planning tool in the previous section for 16 QAM and QPSK, respectively. Figure 5 shows also that a degradation of the fade margin at $E S R_{5 \%}$ is about $5.5 \mathrm{~dB}$ can be expected when normal transmit DD is applied. This degradation can be effectively reduced up to $1.5 \mathrm{~dB}$ by applying the spectrum shaping mitigation techniques. In any case, there is still a high fade margin and the application of diversity has not affected the reception. Figure 6 confirms the results for QPSK constellation.

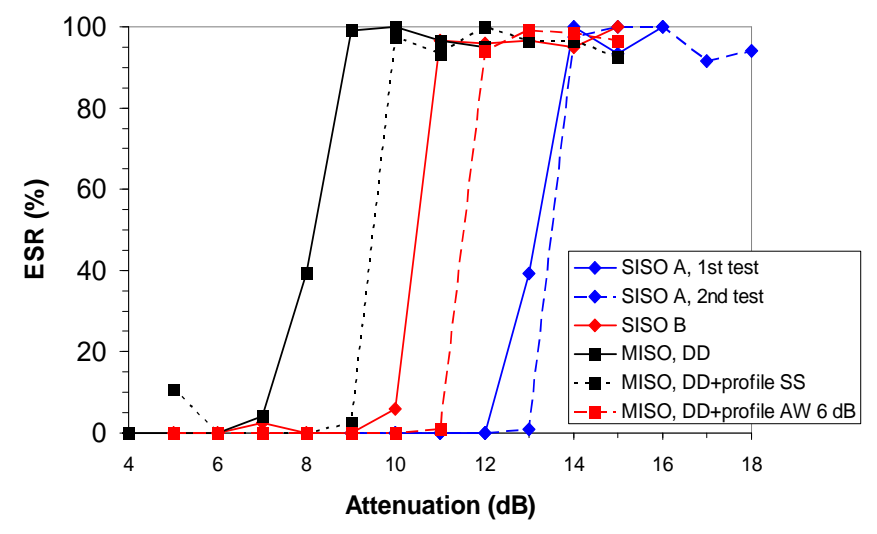

Figure 5: ESR\% vs. input attenuation for LOS Reception, for 16 QAM modulation (25th July)

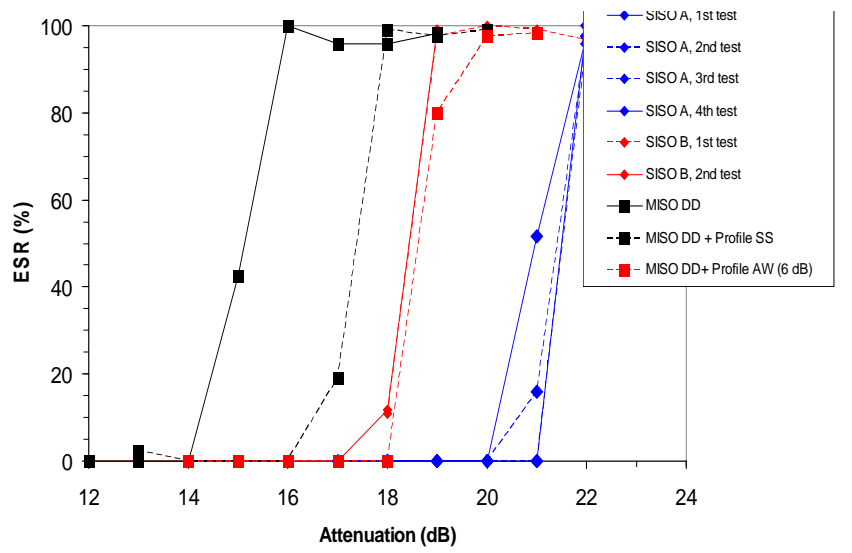

Figure 6: ESR\% vs. Input Attenuation for LOS Reception, for QPSK modulation (16th, 18th, and 21st July)

Results from the measurements performed on different days are shown in Table 3. Table 3 shows the estimated median $\tilde{M}_{F}$ at $\operatorname{ESR}_{5 \%}$ (e.g. $A t t_{5 \%}$ ) and the degradation relative to the best performing SISO transmitter. These measurements show that we can expect degradation in fade margin of some $5.5 \mathrm{~dB}$ and $6.5 \mathrm{~dB}$ at a relatively medium range when normal transmit diversity is applied. These results match well with the 
$6 \mathrm{~dB}$ predicted in [3] for channels with very high Ricean Kfactor. In both modulation cases, the spectrum shaping with Profile AW reduced the LOS degradation of about $4 \mathrm{~dB}$.

TABLE 3: LOS DEGRADATION AT HORSENDEN HILL FOR 16 QAM (A) AND QPSK (B) CASES

\begin{tabular}{|l|c|c|}
\hline \multicolumn{1}{|c|}{ Description } & \multicolumn{2}{|c|}{ 16QAM, 3/4 } \\
\hline & $\begin{array}{c}\text { Median Att } 5 \% \\
\text { (dB) }\end{array}$ & $\begin{array}{c}\text { Gain Relative to } \\
\text { SISO A (dB) }\end{array}$ \\
\hline SISO A (1 test) & 12.5 & - \\
\hline SISO B (1 test) & 10 & - \\
\hline MISO, DD (1 test) & 7 & -5.5 \\
\hline $\begin{array}{l}\text { MISO, DD, with Profile SS } \\
\text { (1 test) }\end{array}$ & 9 & -3.5 \\
\hline $\begin{array}{l}\text { MISO, DD, with Profile } \\
\text { AW (6 dB) (1 test) }\end{array}$ & 11 & -1.5 \\
\hline
\end{tabular}

(a)

\begin{tabular}{|l|c|c|}
\hline \multicolumn{1}{|c|}{ Description } & \multicolumn{2}{|c|}{ QPSK, 3/4 } \\
\hline & $\begin{array}{c}\text { Median Att5\% } \\
\text { (dB) }\end{array}$ & $\begin{array}{c}\text { Gain Relative to } \\
\text { SISO A (dB) }\end{array}$ \\
\hline SISO A (4 test repetitions) & 20.5 & - \\
\hline SISO B (2 test repetitions) & 17 & - \\
\hline MISO, DD (1 test) & 14 & -6.5 \\
\hline $\begin{array}{l}\text { MISO, DD, with Profile SS } \\
\text { (1 test) }\end{array}$ & 16 & -4.5 \\
\hline $\begin{array}{l}\text { MISO, DD, with Profile } \\
\text { AW (6 dB) (1 test) }\end{array}$ & 18 & -2.5 \\
\hline
\end{tabular}

(b)

\section{B. Indoor Measurements}

In indoor reception stable results were produced by performing multiple measurements adopting the remote controlled set up. Measurements were performed in two rooms located in two different buildings to investigate the indoor fixed reception. The diversity gain was estimated by comparing SISO and MISO tests performed during random days in different months to ensure uncorrelated fading conditions for the measurements. Data collected during office hours were purposely included in the whole data set to increase the channel variability and thus decorrelate the channel conditions. Measurement sweeps with multiples $E S R_{\%}$ crossing are removed.

Table 4 shows the result of SISO and MISO comparison in the Sport Pavilion Office. This time, the QPSK modulation was chosen to have enough signal margin. The estimated gain is very close to $5 \mathrm{~dB}$. The SISO variance is about $5.1 \mathrm{~dB}$ while the MISO variance reduces to $4.69 \mathrm{~dB}$.

Table 5(a) shows the result of SISO and MISO comparison in the Sport Centre Office. All the MISO cases are presented. The MISO estimated gain is about $2.2 \mathrm{~dB}$ and $1.2 \mathrm{~dB}$ compared to SISO B and SISO A, respectively. The spectrum profiling keeps the same diversity gain or in the case MISO with Profile SS, it reduces the gain of about $1 \mathrm{~dB}$. The gain in this situation is much smaller than the gain measured in Table 4 and expected from simulations and laboratory measurements [5]. However, Figure 7(a) shows that the majority of SISO $A t t_{5 \%}$ falls outside the step attenuation range (e.g. $50 A^{t} t_{5 \%}$ values out of $70 E S R_{\%}$ curves estimation) while Figure 7(b) shows that the majority of MISO Att $5 \%$ falls within the attenuation range (e.g. $50 A t t_{5 \%}$ values out of $70 E S R_{\%}$ curves estimation). Only the $A t t_{5 \%}$ values falling within the attenuation range are considered for the gain estimation. Thus, the measured gain is a conservative value because it does consider the SISO Att $5 \%$ values occurring at a lower attenuation range that would increase the diversity gain.

TABLE 4: NLOS SPORT PAVILION, QPSK

\begin{tabular}{|l|c|c|c|c|c|}
\hline \multicolumn{3}{|c|}{} & \multicolumn{3}{|c|}{ Att $_{5 \%}(\mathrm{~dB})$} \\
\hline $\begin{array}{l}\text { Descrip } \\
\text { tion }\end{array}$ & $\begin{array}{c}\text { No. } \\
\text { Sample } \\
\mathrm{s}\end{array}$ & Median & $\begin{array}{c}\text { Sample } \\
\text { Variance }\end{array}$ & Minimum & Maximum \\
\hline $\begin{array}{l}\text { NLOS, } \\
\text { SISO A }\end{array}$ & 29 & 6.2 & 5.1 & 2.8 & 13.03 \\
$\begin{array}{l}\text { NLOS, } \\
\text { MISO }\end{array}$ & 65 & 11.15 & 4.69 & 4.4 & 15.13 \\
\hline
\end{tabular}

TABlE 5: SPORT CENTRE FOR 16 QAM (A) AND QPSK (B) MODULATION CASE

\begin{tabular}{|c|c|c|c|c|c|}
\multicolumn{1}{|c|}{} & \multicolumn{4}{c|}{ Att $5 \%(\mathrm{~dB})$} \\
\hline $\begin{array}{c}\text { Description } \\
\text { Samples }\end{array}$ & $\begin{array}{c}\text { Median } \\
\text { So. }\end{array}$ & $\begin{array}{c}\text { Sample } \\
\text { Variance }\end{array}$ & Minimum & Maximum \\
\hline $\begin{array}{c}\text { NLOS, } \\
\text { SISO B }\end{array}$ & 69 & 1.34 & 1.09 & 0.033 & 5 \\
\hline $\begin{array}{c}\text { NLOS, } \\
\text { SISO A }\end{array}$ & 20 & 2.05 & 1.6 & 0.29 & 4.12 \\
\hline $\begin{array}{c}\text { NLOS, } \\
\text { MISO }\end{array}$ & 61 & 3.1 & 2.5 & 0.23 & 6.03 \\
\hline $\begin{array}{c}\text { NLOS, } \\
\text { MISO DD } \\
+ \text { Profile SS }\end{array}$ & 32 & 2.23 & 1.6 & 0.16 & 5.06 \\
\hline $\begin{array}{c}\text { NLOS, } \\
\text { MISO DD } \\
\text { + Profile AW }\end{array}$ & 22 & 3.2 & 1.09 & 0.16 & 4.04 \\
\hline
\end{tabular}

(a)

\begin{tabular}{|c|c|c|c|c|c|}
\hline \multicolumn{2}{|c|}{} & \multicolumn{4}{|c|}{ Att $_{5 \%}(\mathrm{~dB})$} \\
\hline $\begin{array}{c}\text { Description } \\
\text { Somples }\end{array}$ & Median & $\begin{array}{c}\text { Sample } \\
\text { Variance }\end{array}$ & Minimum & Maximum \\
\hline $\begin{array}{c}\text { NLOS } \\
\text { SISO A }\end{array}$ & 59 & 6.3 & 5.6 & 0.23 & 10.599 \\
\hline $\begin{array}{c}\text { NLOS } \\
\text { MISO DD }\end{array}$ & 158 & 11.04 & 2.5 & 3.06 & 13.199 \\
\hline
\end{tabular}

(b)

Subsequently, a QPSK configuration was tested in order to have all SISO $A t t_{5 \%}$ values falling within the attenuation range. Figure 7(d) show that the majority of SISO and MISO Att $_{5 \%}$ falls within the attenuation range (e.g. 61 and 157 $A t t_{5 \%}$ values out of 63 and $159 E S R_{\%}$ curves estimation, respectively). The MISO variance of $A t t_{5 \%}$ is greatly reduced (from $5.6 \mathrm{~dB}$ for SISO up to $2.5 \mathrm{~dB}$ for MISO) and resulting in much more stable reception condition with a more predictable threshold level. Table 5(b) summarized the QPSK results for 
SISO and MISO comparison. The observed $5 \mathrm{~dB}$ of diversity gain are very close to the gain estimated in the Sport Pavilion. While MISO DD with Profile AW maintains the same gain of MISO DD, MISO DD with Profile SS reduces it of about 1 $\mathrm{dB}$.

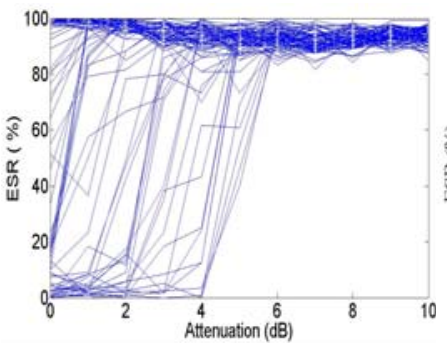

(a)

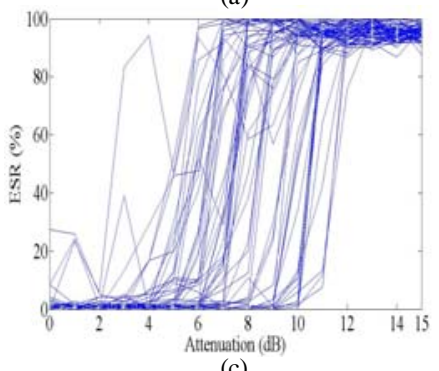

(c)
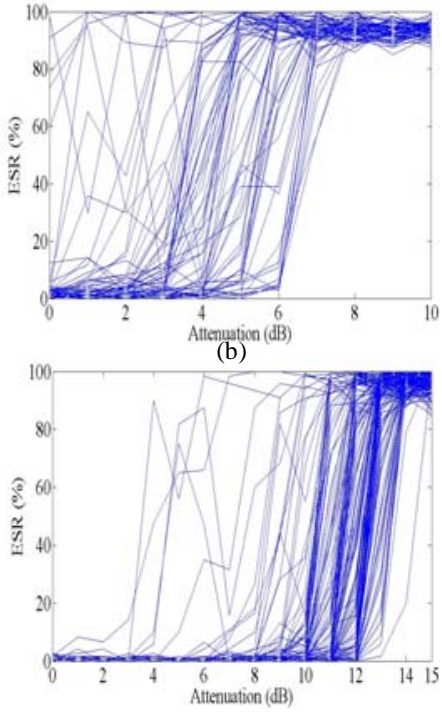

(b)

(d)

Figure 7: Sport Centre ESR\% vs. Input attenuation for SISO 16 QAM (a), MISO 16 QAM (b) SISO QPSK (c) and MISO QPSK (d).

The $5.0 \mathrm{~dB}$ diversity gain presented in this section agrees with laboratory results presented in [2], where a gain of about $5.5 \mathrm{~dB}$ was measured for indoor office with a Root Mean Square (RMS) delays spread of $0.1 \mu \mathrm{s}$, a cross correlation of about 0.25 , a code delay $\delta \approx 1.1 \mu$ s, and a Doppler shift of 1 $\mathrm{Hz}$.

\section{CONCLUSION}

In this paper a long term measurement campaign of MISO DVB-T systems has been presented for testing the DD gain in stationary conditions and for practically analyzing the spectrum profiling techniques for stationary and mobile receptions. The results show that MISO with DD provides a gain of about $5 \mathrm{~dB}$ for indoor propagation channel, characterized by strong NLOS components. Results are obtained by finding the median of several thresholds estimations. For rooftop reception, the dominant LOS component turns the gain over into a performance loss. The maximum estimated loss is $6.5 \mathrm{~dB}$. This range of degradation is confirmed by previous work based on simulation software analysis. Two spectrum profile techniques have been tested in order to reduce the loss for rooftop reception. These techniques can reduce the LOS diversity loss of a $4 \mathrm{~dB}$ factor while reducing the gain up to $1 \mathrm{~dB}$ for NLOS reception. It is envisaged that in rooftop reception, the fade margin is typically high enough to cover this loss because of the high performances aerial. On the other hand, NLOS propagation results generally in lower SNR since the receiver antenna has poor performance and electromagnetic waves are attenuated

by NLOS typical effects like reflections, deflection and refraction. These poor SNR scenarios benefit from DD due to their NLOS characteristic. A maximum reduction of $2.5 \mathrm{~dB}$ for the LOS fade margin and a gain of $5 \mathrm{~dB}$ of fade margin for NLOS is considered to be fairly good trade-off for network planning purposes.

\section{REFERENCES}

[1] A. Dammann and S. Kaiser, "Standard conformable antenna diversity techniques for OFDM systems and its application to the DVB-T system," in Proceedings IEEE Global Communication Conf. (GLOBECOM 2001), USA, pp. 3100-3105, Nov. 2001.

[2] R. Di Bari, M. Bard, Y. Zhang, K.M. Nasr, J. Cosmas, K.K. Loo, R. Nilavalan, H. Shirazi, and K. Krishnapillai, "Laboratory Measurement Campaign of DVB-T Signal with Transmit Delay Diversity," IEEE Trans. on Broadcasting, Vol.54 (3), Part 2, pp. 532-541, Sept. 2008.

[3] A. Dammann, R. Raulefs, S. Plass, "Soft Cyclic Delay Diversity and its Performance for DVB-T in Ricean Channels,” IEEE Global Telecommunications Conference, pp. 4210-4214, Nov. 2007.

[4] W. C.-Y. Lee, and Y. S. Yeh. Polarization Diversity System for Mobile Radio," IEEE Trans. on Communications, vol. COM-20 (5), pp. 912-923, Oct. 1972.

[5] R. Di Bari, M. Bard, A. Arrinda, P. Ditto, J. Cosmas, K.K. Loo, and R. Nilavalan, "Measurement Campaign on Transmit Delay Diversity for Mobile DVB-T/H Systems" submitted to IEEE Transactions on Broadcasting on Oct. 2008.

[6] Digital Video Broadcasting (DVB); Transmission to Handheld Terminals (DVB-H); Validation Task Force $\begin{array}{llllll}\text { Report, } & \text { TR } & 102 & 401 & \text { V1.1.1 European }\end{array}$ Telecommunications Standard Institute ETSI York, 2005

[7] K. Krishnapillai, R. Di Bari, H. Shirazi, J. Cosmas, M. Bard, D. Masse, M. Oksanen, C. Raynal, I. Defee, P. Kasser, "PLUTO Deliverable 3.3, Pilot Trial Facilities including Service Creation System”. Available at: http://dea.brunel.ac.uk/pluto/publications/del3-3.pdf

[8] 12 Element Super Yagi UHF TV Aerial datasheet. Available

at: http://cpc.farnell.com/jsp/level5/module.jsp?moduleId=c $\mathrm{pc} / 467345 . \mathrm{xml}$

[9] J. Goldhirsh, W. Vogel, "Roadside tree attenuation measurements at UHF for land mobile satellite systems," IEEE Trans. on Antennas and Propagation, Vol.35 (5), pp. 589-596, May 1987.

[10] Terrain database for radio mobile. Available at: http://www.cplus.org/rmw/dataen.html

[11] Radio Mobile software website. Available at: http://www.cplus.org/rmw/english1.html 